Apr 2016, Volume 1, Issue 1 (6 - 9)

\title{
Drug-related Atrioventricular Block: Is It a Benign Condition?
}

\author{
Sima Sayah ${ }^{1}$, Mohammad Ali Akbarzadeh ${ }^{2,3,}{ }^{,}$, Zahra \\ Emkanjoo ${ }^{4}$, Reza Mollazadeh ${ }^{5}$, Shahab Shahrzad ${ }^{4}$, Negar \\ Bahrololoumi Bafruee ${ }^{6}$ \\ ${ }^{1}$ Cardiology Department, Ghazvin University of Medical Sciences, Ghazvin, Iran \\ ${ }^{2}$ Cardiovascular Research Center, Shahid Beheshti University of Medical Sciences, \\ Tehran, Iran \\ ${ }^{3}$ Department of Cardiology, School of Medicine, Shahid Beheshti University of \\ Medical Sciences, Tehran, Iran \\ ${ }^{4}$ Department of Pacemaker and Electrophysiology, Shaheed Rajaei Cardiovascular \\ Medical and Research Center, Iran University of Medical Sciences, Tehran, Iran \\ ${ }^{5}$ Emamkhomeini Hospital Complex, Tehran University of Medical Sciences, \\ Tehran, Iran \\ ${ }^{6}$ Razi Hospital, Tehran University of Medical Sciences, Tehran, Iran \\ * Corresponding author: Mohammad Ali Akbarzadeh. Cardiovascular Research \\ Center, Shahid Modarres Hospital, Saadat Abad Street, Tehran, Iran. Tel: +98- \\ 9173171001, E-mail: akbarzadehali@sbmu.ac.ir
}

DOI: $10.20286 /$ ijcp-010105

Submited: 22.07 .2015

Accepted: 02.08.2015

\section{Keywords:}

Atrioventricular Block

Prognosis

Calcium Channel Blockers

(C) 2016. International Journal of Cardiovascular Practice.

\begin{abstract}
Introduction: Prognosis of the patients with beta blocker or calcium channel blocker induced AV block is not well known to date.

Methods: All patients with symptomatic second-degree or third-degree atrioventricular block (AV) referred to our institution during one year were recuited prospectively and classified in two groups based on drug consumption (beta blocker/calcium channel blocker versus none). They were followed for six months and then collected data was analyzed.

Results: The study included 49 patients, 28 patients (age 60.1 $\pm 20,19$ male) did not use any beta blocker or calcium channel blocker (No- DU group) and other 21 patients (age $73.5 \pm 10.4,7$ male) receivd beta blocker, calcium channel blocker or both at the time of AV block (DU group). No-DU group was significantly younger than DU group. The most common atrial rhythm in both groups was sinus. There was no significant difference in QRS wideness or ventricular rate. AV block regressed in $43 \%$ of the DU group after discontinuation of drug for five half-life, but, Mobitz type 2 or complete AV block occurred again during six months in $50 \%$ of them without consumption of the culprit drug.

Conclusions: More than two third of the patients who developed AV block on beta blocker and/or calcium channel blocker needed permanent pacemaker in six months of follow- up, so we concluded that the development of AV block was not as benign as it seems in these patients.
\end{abstract}

\section{INTRODUCTION}

According to ACC/AHA/HRS 2008 Guideline, permanent pacemaker implantation is indicated for third degree and advanced second-degree atrioventricular block (AV) at any anatomic level associated with symptomatic bradycardia or ventricular arrhythmias presumed to be due to AV block and also is indicated in symptom-free patients in sinus rhythm, with documented periods of asystole greater than or equal to 3.0 seconds, any escape rate less than 40 beat per minute $(\mathrm{bpm})$, or with an escape rhythm that is below the AV node (class I) [1]. However, pacemak- er implantation is generally considered unnecessary if it caused by reversible etiologies such as electrolyte abnormalities [1].

It is documented that drugs such as calcium channel blockers and beta blockers, prolong AV nodal conduction and refractoriness in humans may cause $\operatorname{AV}$ block $[2,3]$. But since the significant bradycardia is rare with therapeutic doses in normal heart [4], one of the theories can be unmasking of underlying AV node or hiss-purkinje diseases caused by these medications. So prognosis and natural history of the patients with drug related AV block need to be investigated. 


\section{METHODS}

This prospective study was designed for assessment of mid term prognosis in patients with drug induced AV block. The study protocol was reviewed, and approved by the Review Board of Shaheed Rajaei Cardiovascular Medical and Research Center, and Iran University of Medical Sciences High Research Council. All patients with symptomatic second-degree or third-degree AV block referring to our institution between April 2010 and April 2011 were prospectively collected. Patients with concomitant myocardial infarction, electrolyte abnormalities, digitalis toxicity, vasovagal syncope, and those taking class I or III antiarhythmics were excluded.

The type of AV block was determined by the surface electrocardiogram (ECG). Patients were classified into two groups to define a relationship between beta-blocker or calcium channel blocker therapy and AV block: (1) patients who developed AV block in the absence of drugs that affect AV conduction (No-DUgroup), (2) patients in whom AV block occurred on beta-blockers or calcium channel blockers therapy (DU-group).

Patients in group 2 were subclassified as follows: (1) patients in whom AV block resolved after the discontinuation of drug after 5 half-life (Soon-AVB-R) (2) patients in whom AV block was not resolved and persisted in spite of discontinuation of drug (Soon-AVB-NR).

All patients were monitored continuously during their hospitalization course until they had improved AV conduction within 4-6 days or received an implanted pacemaker (if AV block did not resolve). Patients with apparently normal AV conduction after discontinuation of drug, were discharged and recommended to visit arrhythmia clinic, for evaluation of AV conduction with surface ECG. Patients who had pacemaker placement have been followed in pace maker clinic on a regular basis.

Permanent pacemaker was implanted for all of the patients with recurrence of AV block during follow-up. Collection and analysis of data were authorized by the ethics committee of the hospital. Data were expressed as mean \pm SD. Student's T test, Chi square test and Fisher's exact probability test were used to analyze the data. Results were considered significant at an error probability level of $\mathrm{P}<0.05$.

\section{RESULTS}

Twenty eight of 49 patients who met the criteria and entered the study, didn't use any beta blocker or calcium channel blocker (No-DU group). Mean age of this group was $60.1 \pm$ 20 years, $32.1 \%$ were female and $67.9 \%$ were male (Table 1 ). Other 21 patients with mean age of $73.5 \pm 10.4$ years $(66.7 \%$ female; $33.3 \%$ male) were receiving beta blocker $(81 \%)$, calcium channel blocker $(9.5 \%)$ or both $(9.5 \%)$ at the time of AV block (DU group). This group was significantly older than No-DU group $(\mathrm{P}=0.04)$ and dominantly was female $(\mathrm{P}$ $=0.02)$ (Table 1).

Although Sinus rhythm was the most common atrial rhythm in both No-DU and DU patients $(92.9 \%$ and $95.2 \%$, respectively), the degree of AV block seemed to be some what different in both groups. In No-DU group, no patient had Mobitz type I (Wenckebach) AV block, 7.1\% had Mobitz type 2, and $92.9 \%$ had 3rd degree AV block compared to 4.8, 33.3 and 61.9 in DU group, respectively. QRS duration and also ventricular rate were not significantly different between both groups (Table 1).

\section{Follow-up after Five Half Life of Drug}

AV block regressed in 43\% (9 of 21) of the DU patients with discontinuation of drug after 5 half life (Soon-AVB-R). Mean age of this subgroup was $69.7 \pm 10$ years $(55.6 \%$ female; $44.4 \%$ male).The remained $57 \%$ patients whose AV blocks persist in spite of discontinuation of drug (Soon-AVBNR) candidate for permanent pacemaker implantation. The mean age of this subgroup was $76.4 \pm 10$ years ( $75 \%$ female; $25 \%$ male) which was not significantly different from previous subgroup. Analysis of these two subgroups didn't show any significant differences in degree of AV block, QRS duration, and ventricular rate (Table 2 ).

\begin{tabular}{|c|c|c|c|}
\hline & $\begin{array}{c}\text { AV Block During Drug } \\
\text { Therapy, }(\mathbf{n}=21)\end{array}$ & $\begin{array}{l}\text { AV Block Without } \\
\text { Drugs, }(\mathbf{n}=\mathbf{2 8})\end{array}$ & P Value \\
\hline Age (y) & $73.5 \pm 10.4$ & $60.1 \pm 20$ & 0.04 \\
\hline Male Gender & $7(33.3)$ & $19(67.9)$ & 0.02 \\
\hline Sinus rhythm & $20(95.2)$ & $26(92.9)$ & 1.0 \\
\hline Level of block & & & 0.01 \\
\hline Wenckebach & $1(4.8)$ & $0(0)$ & \\
\hline Mobitz type 2 & $7(33.3)$ & $2(7.1)$ & \\
\hline Complete AV block & $13(61.9)$ & $26(92.9)$ & \\
\hline QRS duration $>120 \mathrm{msec}$ & $12(57.1)$ & $10(35.7)$ & 0.16 \\
\hline Ventricular rate $<40 \mathrm{bpm}$ & $13(65)$ & $22(78.6)$ & 0.34 \\
\hline
\end{tabular}

Data are presented as mean \pm SD and No. (\%). 


\begin{tabular}{|c|c|c|c|}
\hline & $\begin{array}{l}\text { AV Block Regressed after Discon- } \\
\text { tinuation of Drug, }(\mathbf{n}=9)\end{array}$ & $\begin{array}{l}\text { AV Block Remained after Dis- } \\
\text { continuation of Drug, }(n=12)\end{array}$ & P Value \\
\hline Age (y) & $69.67 \pm 10$ & $76.42 \pm 10$ & 0.14 \\
\hline Male Gender & $4(44.4)$ & $3(25)$ & 0.40 \\
\hline Level of block & & & 0.79 \\
\hline Wenckebach & $0(0)$ & $1(8.3)$ & \\
\hline Mobitz type 2 & $4(44.4)$ & $3(25)$ & \\
\hline Complete AV block & $5(55.6)$ & $8(66.7)$ & \\
\hline QRS duration > $120 \mathrm{msec}$ & $4(44.4)$ & $8(66.7)$ & 0.40 \\
\hline Ventricular rate $<40 \mathrm{bpm}$ & $4(44.4)$ & $4(33.3)$ & 0.67 \\
\hline
\end{tabular}

Data are presented as mean \pm SD and No. $(\%)$.

\begin{tabular}{|c|c|c|c|}
\hline & $\begin{array}{c}\text { Drug User-Drug Related AV } \\
\text { Block* } \\
(\mathrm{n}=4)\end{array}$ & $\begin{array}{l}\text { Drug User-Non-Drug Related } \\
\text { AV Block ** } \\
(\mathbf{n}=16)\end{array}$ & P Value \\
\hline QRS duration $>120 \mathrm{msec}$ & $2(50)$ & $10(62.5)$ & 0.64 \\
\hline Ventricular rate $<40 \mathrm{bpm}$ & $2(50)$ & $4(26.7)$ & 0.32 \\
\hline
\end{tabular}

*Patients with AV block during drug consumption whose AV block regressed with discontinuation of medication and didn't relapse in sixmonths of follow- up

** patients with AV block during drug consumption whose AV block didn't regressed or relapse in six moths of follow - up despite the discontinuation of drug.

Data are presented as No. (\%).

\section{A Six-month Follow-up}

In a six-month follow-up, one of the cases missed, in SoonAVB-R group, $50 \%$ developed Mobitz type 2 or complete AV block that needed permanent pacemaker implantation. On the other side, $8.3 \%$ (one case) of the Soon-AVB-NRs in the absence of drug therapy (with betablocker and/or calcium channel blocker) and 3.6\% (one case) of No-DUs showed disappearance of AV block and restoration of sinus rhythm in follow up. (Table 3)

If we pool all the patients with AV block during drug consumption who needed permanent pacemaker implantation till six months of follow-up as drug users, not drug related AV block group (DU-NDR), and who didn't need permanent pacemaker implantation as drug users, drug related group (DU-DR), and compare them, again there will be no significant differences according to QRS duration or ventricular rate.

\section{DISCUSSION}

In our study, most of the patients with AV block in No-DU was male, but most of the patients in DU was female. This can be concluded that increasing female consuming beta blockers or calcium channel blocker or these kinds of drugs results in increasing AV blocks. However, the main finding of our study was that nearly one half of the patients admitted in the hospital due to AV block (except those caused by digoxin toxicity, myocardial infarction, electrolyte imbalance and vasovagal response) was on beta blocker and/or calcium channel blocker. Drugs were discontinued in all of these patients, but in $43 \%$ of them, AV block didn't regress, and in $50 \%$ of them AV block resolved, relapse was seen in less than six months. So it seems that about $70 \%$ of patients who was on beta blocker and/or calcium channel blocker at the time of AV block, permanent pacemaker was needed in six months of follow-up.

There are few other studies with the same result $[5,6]$. A recent study reported that only $15 \%$ of AV blocks in patients treated with beta-blockers and/or calcium channel blocker, is truly caused by these drugs and in others, drug was only 'innocent bystanders' [5]. The authors concluded that as the effect of these drugs is slowing down the conduction of SA node and AV node and this would decrease conduction block in infra- nodal pathways, so in these patients, infra- nodal conduction disease expected to be more severe. In our study, we couldn't find any relationship between QRS duration or ventricular rate (as signs of supranodal or infra -nodal disease) [7-9] and AV block in drug users; in other word, ECG finding of supra or infra nodal block is not a predictor of permanent pacemaker requirement in patients who consumes drug and are on AV block.

Another study that assessed the prognosis of bradycardia related to drugs, evaluated 38 patients with symptomatic bradycardia during beta blocker or calcium channel blocker consumption, and showed that in 10 of 38 cases, bradycardia were not caused by drugs, but were revealed by drugs [10]. Interestingly, in this study, if we omit cases with AV block from that 31 patients who came with symptomatic sinus bradycardia, 27(87\%) patients with bradycardia will be resolved by discontinuation of drugs [10].

Comparing these studies, one can argue when a patient referred due to symptomatic bradycardia on beta blocker or calcium channel blockers, if the bradycardia is caused by the second or third degree AV block, it is less probably that the drug induces and if it is caused by sinus bradycardia it is most probably that the drug induces and will regress by discontinuation of drug.

Study limitation: 1) We studied 49 cases prospectively and this limited numbers of patients prevent subgroup analysis. So some important features such as the effect of drug dose, 
which may be a predictor of reversibility, were not evaluated in this study. 2) Although most of the clues in this and previous studies are compatible with infra -nodal disease of cases who developed AV block on beta blocker or calcium channel blocker, the studies on electrophysiology is needed.

\section{ACKNOWLEDGEMENTS}

The study has been supported by Cardiac Electrophysiology research center, Rajaie Cardiovascual Medical and Research Center, Tehran University of Medical Sciences and Cardiovascular Research Center, Shahid Beheshti University of Medical Sciences, Tehran, Iran.

\section{CONFLICT OF INTEREST}

There is no conflict of interest for the present study.

\section{REFERENCES}

1. Epstein AE, DiMarco JP, Ellenbogen KA, Estes NA, 3rd, Freedman RA, Gettes LS, et al. ACC/AHA/HRS 2008 Guidelines for Device-Based Therapy of Cardiac Rhythm Abnormalities: a report of the American College of Cardiology/American Heart Association Task Force on Practice Guidelines (Writing Committee to Revise the ACC/AHA/ NASPE 2002 Guideline Update for Implantation of Cardiac Pacemakers and Antiarrhythmia Devices) developed in collaboration with the American Association for Thoracic Surgery and Society of Thoracic
Surgeons. J Am Coll Cardiol. 2008;51:e1-62. http://www.ncbi.nlm. nih.gov/pubmed/18498951

2. Husaini MH, Kvasnicka J, Ryen L, Holmberg S. Action of verapamil on sinus node, atrioventricular, and intraventricular conduction. Br Heart J. 1973;35:734-7. http://www.ncbi.nlm.nih.gov/pubmed/4718824

3. Prystowsky EN. The effects of slow channel blockers and beta blockers on atrioventricular nodal conduction. J Clin Pharmacol. 1988;28:6-21. http://www.ncbi.nlm.nih.gov/pubmed/2450898

4. Hauser TH, Pinto DS, Josephson ME, Zimetbaum P. Safety and feasibility of a clinical pathway for the outpatient initiation of antiarrhythmic medications in patients with atrial fibrillation or atrial flutter. Am J Cardiol. 2003;91:1437-41. http://www.ncbi.nlm.nih.gov/ pubmed/12804730

5. Zeltser D, Justo D, Halkin A, Rosso R, Ish-Shalom M, Hochenberg M, et al. Drug-induced atrioventricular block: prognosis after discontinuation of the culprit drug. J Am Coll Cardiol. 2004;44:105-8. http:// www.ncbi.nlm.nih.gov/pubmed/15234417

6. Osmonov D, Erdinler I, Ozcan KS, Altay S, Turkkan C, Yildirim E, et al. Management of patients with drug-induced atrioventricular block. Pacing Clin Electrophysiol. 2012;35:804-10. http://www.ncbi.nlm. nih.gov/pubmed/22530749

7. Wogan JM, Lowenstein SR, Gordon GS. Second-degree atrioventricular block: Mobitz type II. J Emerg Med. 1993;11:47-54. http://www. ncbi.nlm.nih.gov/pubmed/8445186

8. Rardon D, Miles W, Zipes D. Atrioventricular Block and Dissociation. Philadelphia, PA: W.B. Saunders Co.; 2000.

9. Rosen KM, Gunnar RM, Rahimtoola SH. Site and type of second degree A-V block. Chest. 1972;61:99-100. http://www.ncbi.nlm.nih.gov/ pubmed/5058908

10. Lee JH, Ryu HM, Bae MH, Kwon YS, Lee JH, Park Y, et al. Prognosis and natural history of drug-related bradycardia. Korean Circ J. 2009;39:367-71. http://www.ncbi.nlm.nih.gov/pubmed/19949620 